\title{
A Method to Estimate Plant Manager's Skills Quantitatively in the Chemical Industry
}

\author{
Hajime Eguchi ${ }^{\mathrm{a},{ }^{*},}$, Ichiro Koshijima ${ }^{\mathrm{b}}$

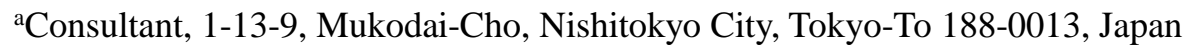 \\ ${ }^{b}$ Nagoya Institute of Technology, Gokiso-Cho, Showa-Ku, Nagoya City, Aichi-Ken 466-8555, Japan \\ *Corresponding Author: h.e@ triton.ocn.ne.jp
}

\begin{abstract}
In the chemical industry, the members who join in the production activity make efforts to improve the productivity of the plant every day. And it is possible to evaluate the productivity with the return of sales and the cost of production. Nevertheless, the human factors in the production cost concern in not only the labor cost but also the skills and knowledge of the production plant personnel. Moreover, the skills and knowledge of production plant personnel affect the resilience that is the capability to restrain a lot of disruptive signals occurred in and out of the production process. The value of skills of the production plant personnel has already been estimated based on the real measured work hours, and the work hours are classified into three types of skills according to the method of self-estimation. This procedure derives three types of resilience. In this paper, this method is expanded to estimate quantitatively the skills of the plant manager who supervises the production process. This quantitative estimation of the skills of the plant manager that contains the resilience as the index of capability will help the improvement of the quality of the daily routines and the resilience of the production process.
\end{abstract}

Keywords: skills, plant manager, resilience, chemical industry, value of skills.

\section{Introduction}

In the production process of the chemical industry, a lot of products are produced by several types of plants. And during the operation of plants, several disruptive signals occur ${ }^{(1,2)}$, start-up and shut-down operation of units, grade shifting, production rate change (in case of a continuous process), set point change etc. The production plant personnel copes with these events. Moreover, the occurrence of some disadvantages requires suitable supervision of plant manager. At first, the high and abundant skills and knowledge of production plant personnel is necessary to practice the smooth production operation. To realize higher resilience ${ }^{(1,2)}$ (the capability to restrain many disruptive signals that occur in and out of the production process) of the production process, and the skills of plant manager who supervises the production plant personnel is also important. Accordingly, the company should provide the opportunity to gain a lot of skills and knowledge for the production plant personnel, and the plant manager has to support them. The index to evaluate activity of the production is the productivity. It depends on a sales amount and a cost of production. However, the productivity is sensitive widely to the outside issues of the production process. So the company tends to depend on the reduction of the human cost. As a result of this company's policy, the total amount of skills and knowledge of the production plant personnel will decrease gradually. And the reduction of manpower will provoke several kinds of plant issues, i.e., accidents and troubles of the equipment, and bring a lot of damage from disasters. Consequently, the productivity will deteriorate, i.e., the human factors are very critical to keep higher productivity.

As the skills and knowledge of the production plant personnel affect the resilience of the production process, the company has to improve the level of skills and knowledge of the production plant personnel with the education and training ${ }^{(3)}$. Moreover, the role of the production plant personnel is very critical to understand the real situation of the production process based on and to maintain always high resilience of the production process ${ }^{(3,4,5)}$. The estimation of skills of the production plant personnel is possible ${ }^{(6,7)}$. In this paper, the method to estimate the skills of the production plant personnel is expanded to that of the plant manager.

At first, based on the real measured work hours of the plant manager, the work hours devoted to skills (hereafter referred to as WHDS) are calculated, and the suitability of skills and the resilience of production process are multiplied to WHDS. The result of this calculation is the value of skills (hereafter referred to as 
VOS) executed by the plant manager. The resilience contained in VOS of the plant manager indicates the capability of supervision And the critical role of the plant manager is to improve the resilience of the production process generated by the production plant personnel, by the production support system (hereafter referred to as PSS; computer system implemented to the production process to improve the productivity), and by the production unit. As the plant manager cannot generate directory the resilience of the production process, it is necessary to supervise three types of resilience produced in the production process. The relationship between VOS of the members to operate a production process (plant manager and three production plant personnel) and the three types of the resilience of a production process produced in the production process are shown in Fig. 1. This operation team is a real one, the relation of VOS and the resilience of this production process have been examined in the former papers ${ }^{(3,4,5)}$. In this research, the procedure to evaluate the capability of the plant manager quantitatively is shown, and this ability contains the resilience of the production plant that the plant manager supervises.

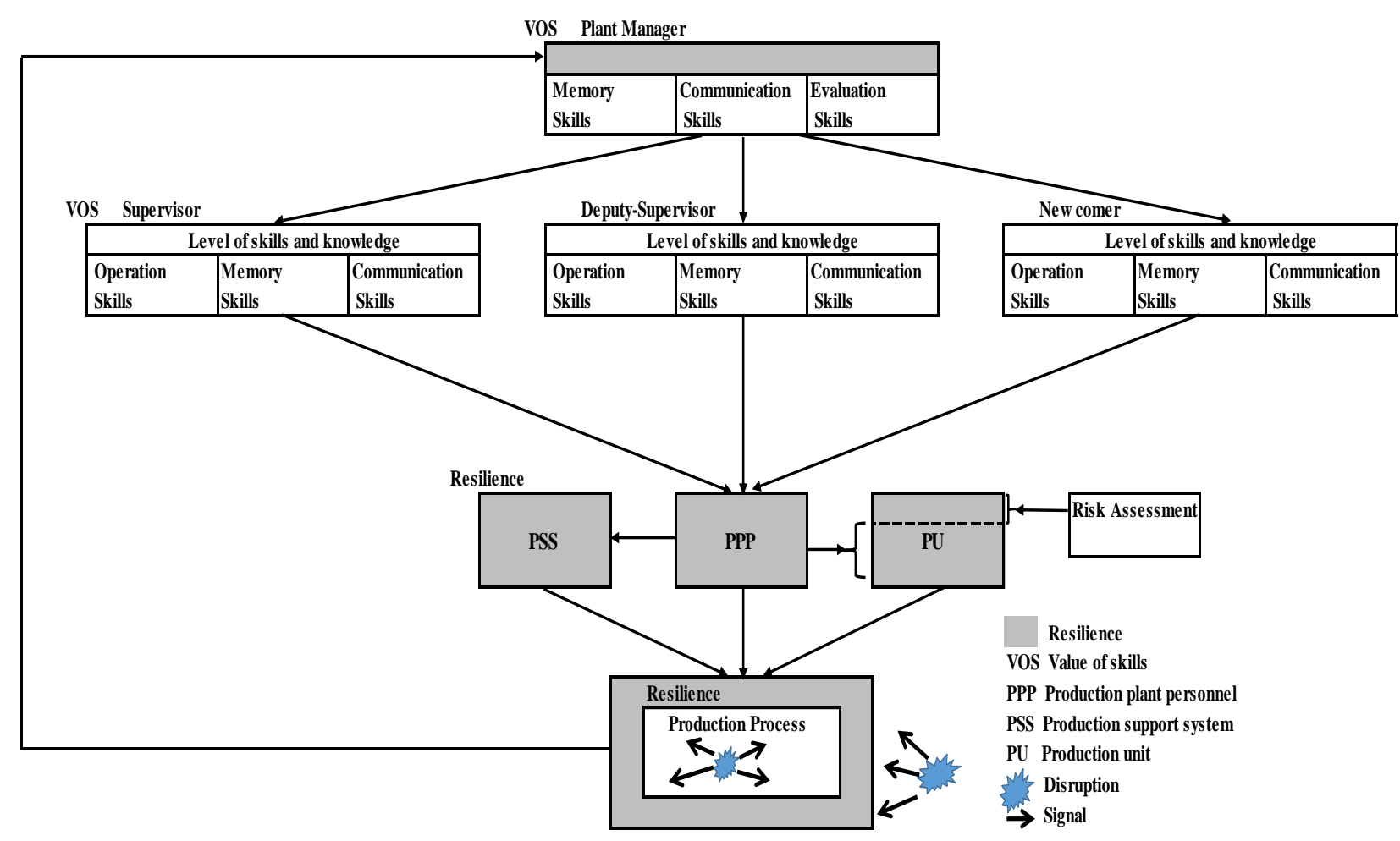

Fig.1. Relationship between VOS and resilience

\section{Skills of Plant Manager}

In the chemical factory, the plant manager is indispensable to practice a sooth production activity by adequate supervision. The plant manager supervises the production plant personnel. The skills of the plant manager is generally considered as the individual property, consequently, the universal standard to evaluate the skills quantitatively doesn't exist yet. The company has the criterion to assess the plant manager every year to decide the salary, nevertheless, it is different from the evaluation of the skills quantitatively. Therefore, in this paper, the method to estimate the skills of the plant manager quantitatively, and to demonstrate its efficient usage is proposed. At first, the classification category of the skills of the plant manager is defined and based on the real measured work hours in the daily routine, WHDS is estimated. After that, VOS is estimated. The authors have already proposed a method to calculate VOS concerning the production plant personnel (3). Here, using this technique, VOS of the plant manager is estimated quantitatively. The classification of skills are as follows:

1) Memory skills: skills to utilize the historical data and former experience for the smooth operation of the production process. Memory skills are not very important as other skills of the plant manager.

2) Communication skills: skills to communicate with the production plant personnel, the superiors and the person concerned. The plant manager is desired to have Communication skills commonly. 
3) Evaluation skills: skills to evaluate various data concerning the smooth production activity. Evaluation skills are desirable for the plant manager.

In the case of the production plant personnel, these categories are as follows.

1) Operational skills: skills to operate the equipment and to enter in any operational reports.

2) Memory skills: skills to use some experience to execute the smooth operation.

3) Communication skills: skills to keep a good relationship in and out of job group.

The desirable skills for the plant manager and the production plant personnel are different, and in a respective item of skills, the suitability is also different. Accordingly, the members in the production activity should practice desirable skills. And to explain the desirability in the categories of skills, the pair-wise comparison matrix is defined to get the weighting vector to indicate the suitability of each skill for the position of the plant manager. Next, the real measured work hours of the plant manager for the daily routine is converted to WHDS by self-estimation. Moreover, these weighted WHDS multiplied by the capability of supervision (averaged value of three types of the resilience of the production process) brings VOS of the plant manager.

\subsection{Example of the estimation of VOS}

It is possible to estimate the VOS in the case of plant manager as follows (see Fig. 2.)

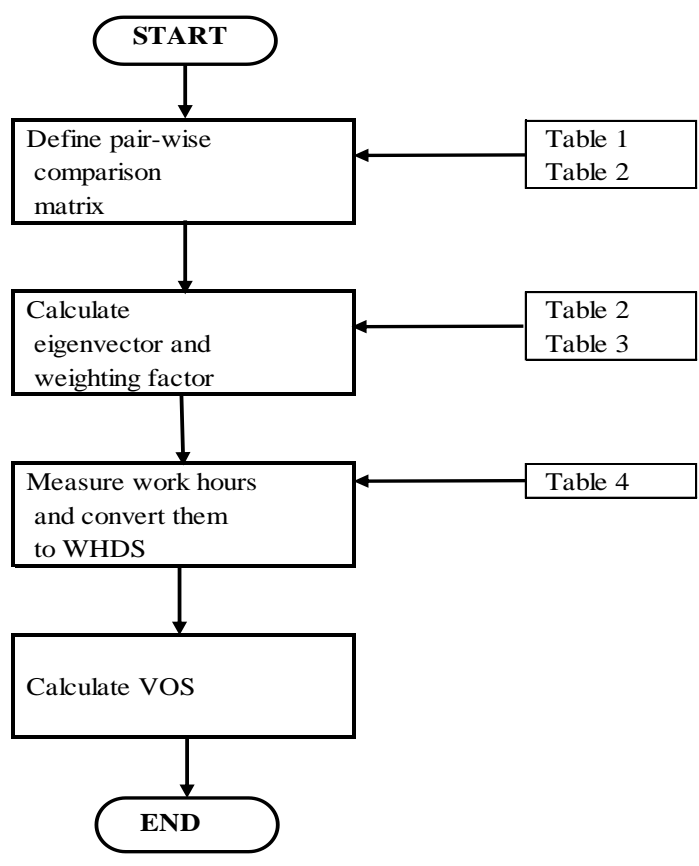

Fig.2. Procedure to calculate VOS

1) Define comparison scale (see Table 1.). And the components of pair-wise comparison matrix to reflect the suitability of skills in the position of plant manager are defined (see Table 2.).

Table 1. Comparison Scale

\begin{tabular}{lll}
\hline Comparison of the component $\mathrm{i}$ with $\mathrm{j}$ & $\rightarrow$ & $\mathrm{a}_{\mathrm{ij}}$ \\
\hline $\mathrm{i}$ and $\mathrm{j}$ are of equal priority & $\rightarrow$ & 1 \\
$\mathrm{i}$ is weakly prior to $\mathrm{j}$ & $\rightarrow$ & 2 \\
$\mathrm{i}$ is strongly prior to $\mathrm{j}$ & $\rightarrow$ & 3 \\
$\mathrm{i}$ is very strongly prior to $\mathrm{j}$ & $\rightarrow$ & 4 \\
$\mathrm{i}$ is absolutely prior to $\mathrm{j}$ & $\rightarrow$ & 5 \\
\hline
\end{tabular}

Table 2. Pair-wise Matrix for Plant Manager $\boldsymbol{A}$

\begin{tabular}{|c|c|c|c|}
\hline $\mathrm{a}_{\mathrm{ij}}$ & 2)Memory skill & $\begin{array}{l}\text { 3)Communication } \\
\text { skill }\end{array}$ & 3) Evaluation skills \\
\hline 1)Memory skills & 1 & $1 / 2$ & $1 / 3$ \\
\hline $\begin{array}{l}\text { 2)Communication } \\
\text { skills }\end{array}$ & 2 & 1 & $1 / 2$ \\
\hline 3)Evaluation skills & 3 & 2 & 1 \\
\hline
\end{tabular}

Table 3. Eigen Vector and Weighting Vector $\boldsymbol{W} 1$

\begin{tabular}{lc}
\hline & Plant manager \\
\hline Eigenvector & 0.2724 \\
& 0.4662 \\
& 0.8417 \\
\hline Maximum & 3.0621 \\
Eigenvalue $\lambda_{\max }$ & \\
\hline Consistency & 0.03105 \\
CI & \\
\hline Weighting vector & 0.5740 \\
$\boldsymbol{W} 1$ & 0.9823 \\
& 1.7785 \\
\hline
\end{tabular}

First, the eigenvector and eigenvalue of pair-wise comparison matrix $\boldsymbol{A}$ are calculated (see Table 3.). Selected eigenvector's components are normalized to obtain weighting vector $\boldsymbol{W} 1$ that indicates the suitability or desirability of skills. As the consistency index, $C I$ is small enough, the pair-wise comparison matrix $\boldsymbol{A}$ is consistent and coherent.

2) Measure the work hours for the daily routine, and classify them into three types of skills (Memory skills, Communication skills, and Evaluation skills) by self-estimation as WHDS $\boldsymbol{B}$.

The daily routines of the plant manager are as follows:

A) Analyze the actual result of the production activity.

B) Evaluate the productivity of the production process.

C) Improve the production efficiency.

D) Rectify of plant issue. 
E) Approve the result of risk assessment.

F) Make a managerial plan of the plant.

G) Direct and evaluate the production plant personnel.

In this case, the daily routines are classified into seven categories, and another plant managers engage in the different group' of routines.

In this example, the total working days per month of the plant manager are 23 , and the working hours per day are 7.5. Therefore, the total work hours of the plant manager are 172.5 .

3) Calculate VOS using the WHDS (see Table 4.).

First, WHDS is weighted by $\boldsymbol{W} 1$ that shows the desirability of skills. Next, weighted WHDS multiplied by the capability of plant manager (the averaged resilience of supervised production process) is VOS.

Table 4. WHDS of Plant Manager $\boldsymbol{B}$

\begin{tabular}{c|c|c|c}
\hline \multicolumn{2}{|c|}{ (hour/month) } \\
\hline Work i & & & \\
\hline A) & 1) Memory skills & 2) Communication skills & 3) Evaluation skills \\
\hline B) & $\mathbf{1 0}$ & $\mathbf{1 5}$ & $\mathbf{1 5}$ \\
\hline C) & $\mathbf{5}$ & $\mathbf{5}$ & $\mathbf{2 0}$ \\
\hline D) & $\mathbf{1 0}$ & $\mathbf{5}$ & $\mathbf{1 0}$ \\
\hline E) & $\mathbf{3}$ & $\mathbf{5}$ & $\mathbf{1 0}$ \\
\hline F) & $\mathbf{1 0}$ & $\mathbf{5}$ & $\mathbf{5}$ \\
\hline G) & $\mathbf{5}$ & $\mathbf{5}$ & $\mathbf{1 0}$ \\
\hline
\end{tabular}

$$
\begin{aligned}
\boldsymbol{T} & =\boldsymbol{B} \cdot \boldsymbol{W} 1 \\
& =\left(\begin{array}{ccc}
10 & 15 & 15 \\
5 & 5 & 20 \\
5 & 5 & 10 \\
10 & 10 & 10 \\
2.5 & 5 & 5 \\
10 & 5 & 10 \\
5 & 5 & 5
\end{array}\right) \cdot\left(\begin{array}{l}
0.5740 \\
0.9823 \\
1.7785
\end{array}\right) \\
& =\left(\begin{array}{c}
47.152 \\
43.3515 \\
25.5665 \\
33.348 \\
15.239 \\
15.239 \\
16.674
\end{array}\right)
\end{aligned}
$$

$Q=T k \cdot C$

$$
=\left(\begin{array}{l}
57.903 \\
53.236 \\
31.396 \\
40.951 \\
18.715 \\
34.920 \\
20.434
\end{array}\right)
$$

Here, $C$ equals to 1.228 , and the calculation of $C$ is shown later.

$$
Q_{\text {total }}=\sum_{i=1}^{Y} Q_{\hat{i}}=257.555
$$

Here, $C$ is an index to indicate the capability of supervision, i.e., $C$ is an average of the resilience of several production processes supervised by the plant manager. There are three categories of resilience in the production process. Resilience produced by Production Plant Personnel ( $\left.R_{\mathrm{PPP}}\right)$, Resilience produced by PSS $\left(R_{\mathrm{PSS}}\right)$, and Resilience produced by Production Unit $\left(R_{\mathrm{PU}}\right)$. The summation of this resilience is that of the production process.

$$
\begin{aligned}
R_{\text {PPP }} \text { is calculated as follows } & { }^{(3,8)} . \\
R_{\text {PPP }} & =\frac{\left.\sum \text { (weightedWHDS } \times \text { levelof skills and knowledge }\right)}{\sum(\text { weightedWHDS })} \\
& =0.993
\end{aligned}
$$

$R_{\text {PPP }}$ is a weighted average of the level of skills and knowledge of the several production plant personnel. In the case of this example, the level of skills and knowledge is from 0.8 to $1.2^{(3,7,8)}$.

$R_{\text {PSS }}$ is calculated as follows ${ }^{(4,8)}$.

$$
R_{\mathrm{PSS}}=\frac{\sum(\text { replaceable WHDS } \times \text { replaceabe levelof skills and knowledge })}{\sum(\text { replaceable WHDS })}
$$$$
=0.173
$$

$R_{\text {PSS }}$ is a weighted average of replaceable WHDS of the production plant personnel with several functions of PSS.

$R_{\mathrm{PU}}$ is calculated as follows ${ }^{(5,8)}$.

$R_{\mathrm{PU}}=R_{\mathrm{PPP}} \times$ Minimum value of IR

$$
=0.062
$$

$R_{\mathrm{PU}}$ is calculated by $R_{\mathrm{PPP}}$ and the index of risk (IR) that is derived from the result of the risk assessment in this production process (see reference (5) in detail).

A plant manager supervises generally several production processes, however in this case the number of supervised production process by the plant manager is one, and its resilience has already estimated ${ }^{(3)}$. This production process is a batch-wise plant operated by three production plant personnel (Supervisor, Deputy-supervisor, Newcomer; each level of skills and knowledge is 1.2, 1.0, and $\left.0.8{ }^{(3)}\right)$.

The summation of three categories of resilience in this production process $\left(R_{\mathrm{PPP}}+R_{\mathrm{PSS}}+R_{\mathrm{PU}}\right)$ is 1.228 . Therefore, in this example, $C=1.228$, and $Q_{\text {total }}=257.555$, i.e., VOS of the plant manager is about $23 \%$ greater than initial VOS calculated by WHDS.

\subsection{Examination of the result of example}

The result of this example contains the self-estimation because the classification of the regular work hours to WHDS is impossible for a third party. However, this method is useful to review the daily routine of the plant manager if it is suitable or not. If the skills practiced in the 
daily routine of the plant manager is not desirable, he/she should review own daily routine. And this trial will improve the skills of the plant manager. Besides, the capability of the plant manager depends on the resilience of the supervised production processes, i.e., VOS of plant manager is the combination of the resilience of the production process and the individual attribute of the plant manager. The resilience of production process depends on the skills and knowledge of the production plant personnel; the plant manager cannot generate the resilience directly in the production process. However, the resilience of the production process is one of the components of VOS of the plant manager as a capability of supervision; the plant manager can influence the resilience of the production process through the skills and knowledge of the production plant personnel. Consequently, the plant manager has to make efforts to improve the skills and knowledge of the production plant personnel and to develop any functions of PSS that are replaceable to the routine of the production plant personnel and to decrease the risk in the production process. The VOS of the plant manager examined here is 257.555 hours during 23 days, and 7.5 hours/day. The work hours during 23 days and 7.5 hours/day are 172.5 hours, however, the VOS is 257.555 hours. Specifically, if the plant manager engages in the routine more desirable as the job position, the VOS increases all the better. The self-estimation is a center of this method and is one of the best ways to improve own efficiency of the job. The approach to improve the skills of the plant manager does not establish now. So this method to estimate the skills of the plant manager quantitatively should be introduced in the company's activity.

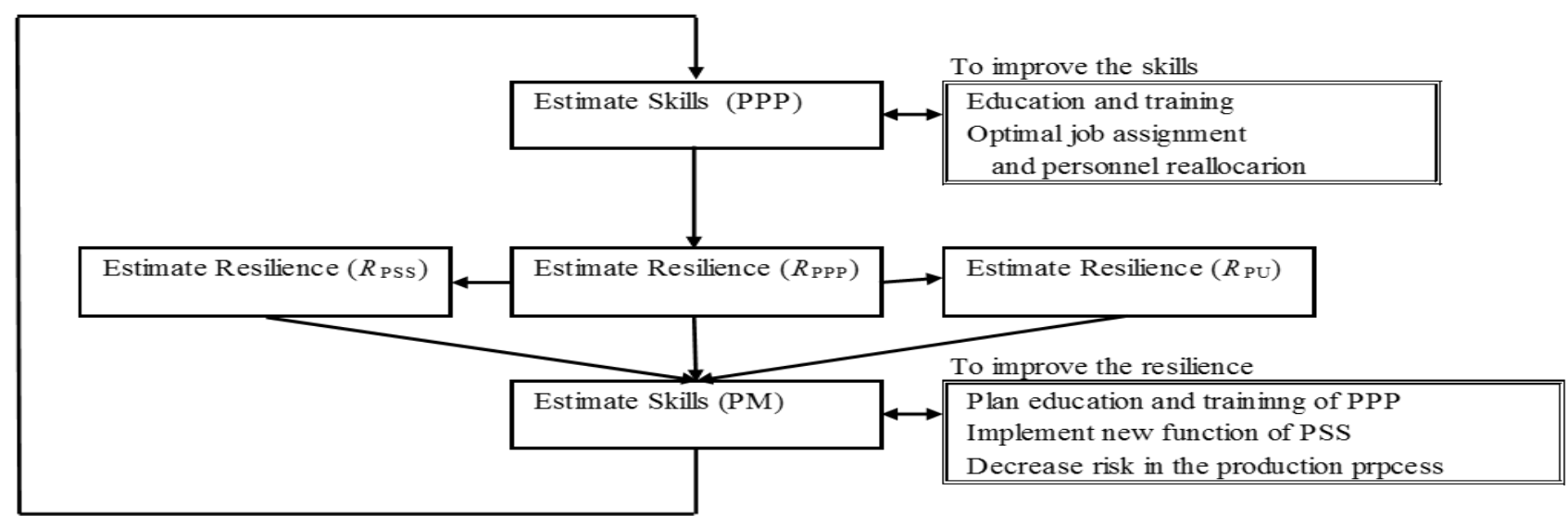

PPP : Production P lant Personnel PSS: Production Support System PM : Plant Manager

Fig. 3. Management cycle of skills and resilience

\section{Conclusion}

The quantitative estimation of the skills of the plant manager in the chemical industry has not been sufficiently researched yet. And the company evaluates the capability of the plant manager to decide the salary every year, nevertheless, the object is not always the skills of the plant manager about the routine. As shown in Fig. 3, the way to improve VOS of the production plant personnel is the education and training ${ }^{(3)}$, and the optimal job assignment ${ }^{(9)}$, and optimal personnel allocation (10). And the approach to improve the resilience of the production process consists of the planning of the education and training of the production plant personnel, and the implementation of new function replaceable to the production plant personnel in PSS ${ }^{(4)}$, moreover the decrease of the risk found as the result of the risk assessment in the production process ${ }^{(5)}$. The method mentioned in this paper is useful to estimate the skills of the plant manager by self-estimation because using this procedure, the plant manager can obtain own target to be attained in the job and the problems that are to be improved personally. And it is also important to direct the production plant personnel carefully according to the program of the education and training in the company. The improvement of the resilience as mentioned above brings the progress of the skills to the plant manager. As the plant manager does not generate the resilience of the production process, and as the VOS of the plant manager contains the resilience of supervised production process, the efforts to increase VOS is very efficient to realize high productivity of the production process in the chemical industry. Next 
Proceedings of the 6th IIAE International Conference on Industrial Application Engineering 2018

objectives of this research are as follows: 1) the analysis of the different change speed of the resilience and WHDS of the plant manager, 2) the estimation of the skills of technical staff who does not supervise the production process. In spite of the existence of the technical staffs, their skills are not evaluated rightly. Moreover, the skills of the senior manager in the factory are not clear. Therefore, it is necessary to show the skills of the senior manager quantitatively to improve the productivity, because the senior manager is a critical person in the factory to work on the creative matters. So, the skills of the senior manager will contain 1) Communication skills, 2) Evaluation skills, and 3) Creativity skills. Moreover, the skills of the top management of chemical factory should also be established.

\section{Acknowledgment}

This research was partially supported by the Ministry of Education, Science, Sports and Culture, Grant-in-Aid for Scientific Research (A), No.16H01837 (2016), and Council for Science, Technology, and Innovation (CSTI), Cross-ministerial Strategic Innovation Promotion Program (SIP), "Cyber- Security for Critical Infrastructure" (funding agency; NEDO).

\section{Reference}

(1) F. Bracco, T. Piccinno and G. Dorigatti : "Turning Variability into Emergent Safety: the Resilience Matrix for Providing Strong Responses to Weak Signals", Proc. of 5th Sympo. on Resilience Engineering Managing Trade-Off, pp. 23-28, 2013

(2) H. Eguchi, T. Aoyama, K. Seki, D. O’Donovan, and I. Koshijima : "ORGANIZATIONAL STRUCTURE ON THE RESILIENCE OF PRODUCTION PROCESSES BASED ON HUMAN FACTORS IN THE CHEMICAL INDUSTRY", J. of Eng. Sci. and Tech. Special Issue on SOMCHE 2014 \& RSCE 2014 Conf., pp. 30 - 40, Jan., 2015
(3) H. Eguchi, T. Aoyama, K. Seki, D. O’Donovan, and I. Koshijima : "A Metric for Quantitative Estimation of Production Process Resilience based on the Skills and Knowledge of Production Plant Personnel in the Chemical Industry", J. of Chem. Eng. of Japan Vol.49, No.1, pp. 1-7, 2016

(4) H. Eguchi, T. Aoyama, K. Seki, and I. Koshijima : “A Metric for Quantitative Estimation of Production Process Resilience generated by Production Support System in the Chemical industry", J. of Chem. Eng. of Japan Vol.49, No.7, pp. 673-679, 2016

(5) D.Nyambayar, I.Koshijima, and H. Eguchi : "A Metric for Quantitative Estimation of Production Unit Based on OSHMS", Proc. of the $29^{\text {th }}$ SOMChE, Dec., 2016

(6) H.Eguchi and D.O'Donovan : "Advancement and Transfer of Skills by Reciprocal Interaction of Human Skills and Techniques via a Production Support System in the Chemical", J. of Chem. Eng. of Japan, Vol. 43, No. 5, pp. 435-442, 2010

(7) H.Eguchi and D. O'Donovan : "Effect of a Change in Personnel on the Quantitative Evaluation of Human Skills in the Chemical Industry", J. of Chem. Eng. of Japan, Vol. 44, No. 1, pp. 32-36, 2011

(8) H. Eguchi, D. Nyambayar, and I. Koshijima : "Contribution of Production Support System to Reinforce Process Resilience in the Chemical Industry", Proc of 6th International Symposium on Advanced Control of Industrial Processes (AdCONIP) pp.400-405, Taipei, May, 2017

(9) H. Eguchi, T. Aoyama, K. Seki, and I. Koshijima : "Optimal Job Routine Assignment for the Improvement of Operational Resilience Based on Skills and Knowledge of Production Staff in the Chemical Industry," Proc. of SCIS\&ISIS 2014 (no.158) Dec., 2014

(10) H. Eguchi, T. Aoyama, K. Seki, and I. Koshijima : "Optimal Personnel Reallocation Based on the Skills and Knowledge in the Chemical Industry", J. of the Institute of Industrial Applications Engineers Vol.3, No.3, pp.126-133, 2015 